\title{
Removal of Chromium by Modified Nano Zero Valent Iron Supported on Carbon Fiber
}

\author{
Shuo LI \\ School of Environmental and Materials Engineering \\ Shanghai Polytechnic University \\ Shanghai 201209, P. R. China \\ e-mail: Shuo975523667@sina.com
}

\author{
Shengwen CHEN \\ School of Environmental and Materials Engineering \\ Shanghai Polytechnic University \\ Shanghai 201209, P. R. China \\ e-mail: Swchen@sspu.edu.cn
}

\author{
Changwen MA \\ School of Environmental and Materials Engineering \\ Shanghai Polytechnic University \\ Shanghai 201209, P. R. China \\ e-mail: Cwma@sspu.edu.cn
}

\begin{abstract}
Using carbon fiber (CF) as carriers and sodium carboxymethyl cellulose (CMC) as modifiers, nano zero valent iron (nZVI) was prepared and characterized by Scanning Electron Microscopy (SEM) and X-Ray Diffraction (XRD). The effects of the different materials, the initial solution $\mathrm{pH}$, and so on, were investigated. The results show that the modified $\mathrm{nZVI}$ has better dispersion and stronger antioxidant activity. CF-CMC-nZVI was proved the best to remove $\mathrm{Cr}$ (VI). The process of removal $\mathrm{Cr}$ (VI) by CF-CMC-nZVI was line with the Langmuir adsorption isotherm and maximum adsorption was $217.04 \mathrm{mg} / \mathrm{g}$.
\end{abstract}

Keywords-nano zero valent iron; cmc; carbon fiber; cr (vi); isothermal adsorption

\section{INTRODUCTION}

Chromium can be found in the atmosphere, soil, water, plants and animals [1]. Different valence of chromium has different toxicities. $\mathrm{Cr}$ (VI) is 100 times higher toxicity than $\mathrm{Cr}$ (III) [2]. Cr (VI) is a kind of carcinogenic substance [3]. Chromium is mainly used in manufacturing industry. All sorts of six valence chromium compound are widely used in leather industry, textile production, and so on. Untreated electroplating waste liquid contained high concentration chromium, which exceeds 1000 times of the discharge standard in China [4]. Therefore, the treatment of excessive chromium is necessary.

The main treatment methods to remove $\mathrm{Cr}$ (VI) are included biological method, precipitation method, and so on [5]. The development of nanometer materials has provided a new solution to remove $\mathrm{Cr}$ (VI) in the environment. Because of large specific surface area, nanometer material has excellent adsorption properties and chemical reaction activity [6]. The method of using ZVI to remove heavy metals has been developed for decades. Research shows micron/nanometer ZVI can reduction or removal of heavy metals effectively. Compared with the larger particle size of the metal particles or traditional adsorption materials, it has advantage of better effect, higher efficiency, faster speed and lower cost. It also can regeneration after being used. Micron/nanometer ZVI can disposal heavy metal, such as $\mathrm{Cr}$, $\mathrm{Cd}, \mathrm{Pb}$, and so on, has been proved [7]. nZVI has the advantages of large specific surface area and strong reduction. On the other side, it is easy to be oxidized and reunited. This phenomenon decreased reaction activity. The addition of stabilizers in the process of preparing nZVI can effectively prevent the aggregation of nZVI and improve the efficiency of removal of $\mathrm{Cr}$ (VI) [8].

\section{MATERIALS AND METHODS}

\section{A. Preparation and Characterization of Different Materials}

The carbon fiber supported modified nZVI was prepared by liquid-phase reduction. A certain amount of $\mathrm{FeSO}_{4} \cdot 7 \mathrm{H}_{2} \mathrm{O}$ and $0.5 \% \mathrm{CMC}$ solution and $\mathrm{CF}$ were added in solution. After dropping the $\mathrm{NaBH}_{4}, \mathrm{CF}$ loaded CMC modified nZVI (denoted as CF-CMC-nZVI) was prepared. All the process was under protection of nitrogen.

According to the above method, CF was added into the CMC modified nZVI solution and then carbon fiber loaded CMC-nZVI (denoted as CMC-nZVI+CF) was obtained; without the addition of CMC modifiers, a carbon fiber supported nZVI (denoted as CF-nZVI) was prepared.

\section{B. Removal of $C r$ (VI) by CF-CMC-nZVI}

Prepare a stock solution of $\mathrm{Cr}$ (VI) concentration about $1000 \mathrm{mg} / \mathrm{L}$ and take a certain volume of $\mathrm{Cr}$ (VI) solution and adjust $\mathrm{pH}$ with sodium hydroxide or sulfuric acid solution. Add a certain prepared materials in solution and sample at intervals and then filter with a $0.45 \mathrm{~m}$ filter. The filtrate was determined by 1,5-dtphenylcarbohydrazide spectrophotometric method [9]. The removal capacity (q) and the removal percentage ( $\mathrm{R} \%$ ) of $\mathrm{Cr}(\mathrm{VI})$ were calculated by Eq. (1) and Eq. (2) [10], respectively.

$$
\mathrm{q}=\frac{\left(\mathrm{C}_{\mathrm{o}}-\mathrm{C}_{\mathrm{e}}\right) \times \mathrm{V}}{\mathbf{m}}
$$




$$
\mathrm{R} \%=\frac{\left(\mathrm{C}_{0}-\mathrm{C}_{\mathrm{e}}\right)}{\mathrm{C}_{0}} \times 100 \%
$$

Where $q$ was the adsorption capacity (mg /g); $\mathrm{C}_{0}$ and $\mathrm{C}_{\mathrm{e}}$ were the initial and residual concentration of $\mathrm{Cr}(\mathrm{VI})$ in solution $(\mathrm{mg} / \mathrm{L})$, respectively.

\section{III.RESULTS AND DISCUSSION}

\section{A. Characterization of Materials}

Fig.1 shows SEM images of different materials. The modified nanoscale zero valent iron has a better dispersion, a larger specific surface area and there was no significant agglomeration. The reunite of nZVI has not been found because of $\mathrm{CMC}$ as a stabilizer prevent the nanometer iron from gathering. CMC-nZVI is coated on the surface of carbon fiber, which forms a composite material, and its mechanical strength is greatly improved. In the process of material preparation, the addition order of carbon fiber is different, and the mechanical strength of the modified nZVI is also different.
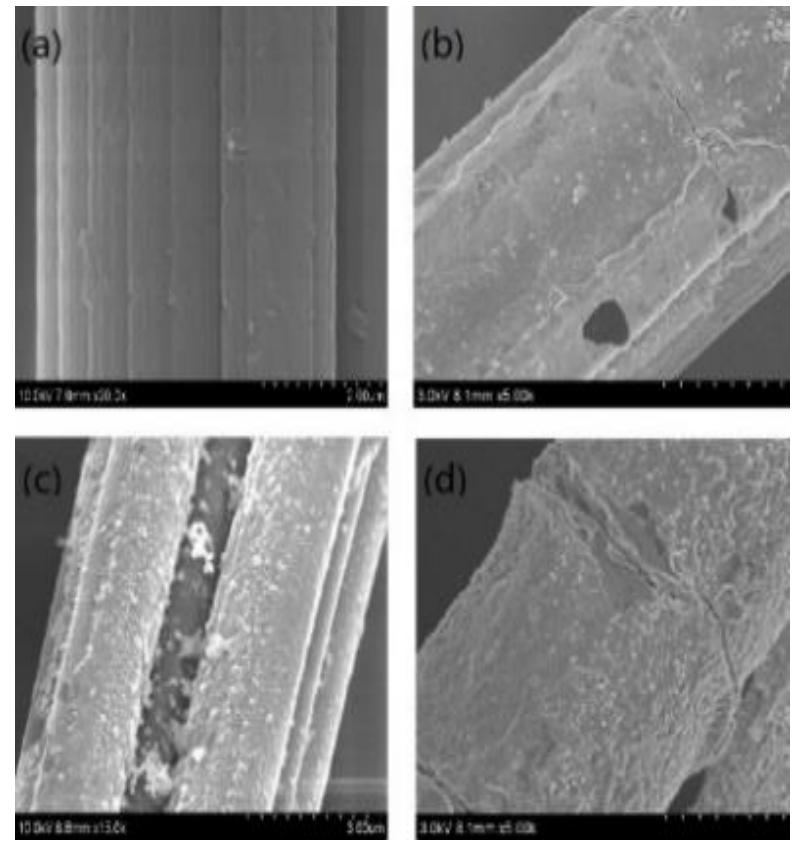

Figure 1. SEM image of (a) CF, (b) CF-CMC-nZVI, (c) CMC-nZVI +CF, (d) CF-nZVI.

Fig.2 shows the X-ray diffraction (XRD) pattern of the CFCMC-nZVI. The diffraction peaks appeared at around $2=$ 25 and $2=45$. The sample appeared clear diffraction peaks at 44.9, which corresponds to $-\mathrm{Fe}^{0}$ the (110) diffraction, indicating that the main component was $\mathrm{Fe}[11]$ and the prepared materials have better oxidation resistance because of the addition of $\mathrm{CMC}$ and $\mathrm{CF}$.

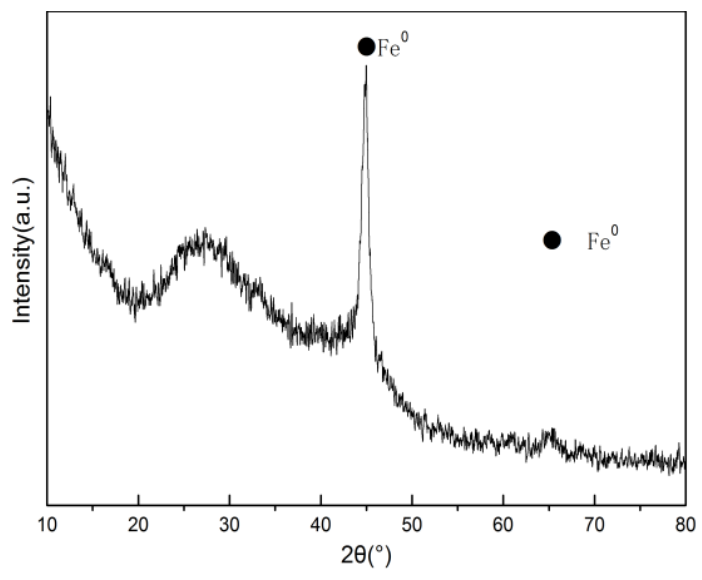

Figure 2. XRD patterns of CF-CMC-nZVI.

\section{B. $C r(V I)$ Removal}

1) Effect of four different materials on $\mathrm{Cr}(\mathrm{VI})$ removal

Fig.3(a) shows that after 3 hours the removal efficiency of $\mathrm{CF}$ to $\mathrm{Cr}(\mathrm{VI})$ was poor, only about $5 \%$; the removal efficiency of CF-nZVI was $23.41 \%$; the removal efficiency of CMC-nZVI+CF was $66.85 \%$ and the removal efficiency of CF-CMC-nZVI to Cr(VI) was $71.99 \%$. CF-CMC-nZVI was the best to remove $\mathrm{Cr}$ (VI) during 4 kinds of materials. The addition of $\mathrm{CF}$ had good effects on the removal of $\mathrm{Cr}$ (VI). In the preparation of CF-CMC-nZVI, CF adsorbed more ferrous ions wrapped by CMC.

2)Effect of solution $\mathrm{pH}$ on $\mathrm{Cr}(\mathrm{VI})$ removal

The effects of $\mathrm{pH}$ on the removal efficiency of $\mathrm{Cr}(\mathrm{VI})$ are presented in Fig.3 (b). The removal rate of $\mathrm{Cr}$ (VI) showed a significant decrease with the increase of initial $\mathrm{pH}$. Accordingly, the removal of $\mathrm{Cr}$ (VI) by nZVI was more favorable under acidic condition, and the removal efficiency was poor in alkaline conditions. Ferrous ions have a stronger reducibility, can reduce $\mathrm{Cr}$ (VI) to $\mathrm{Cr}$ (III). In the acidic solution, $\mathrm{Cr}$ (VI) mainly exists in the form of $\mathrm{Cr}_{2} \mathrm{O}_{7}{ }^{2-}$ or $\mathrm{HCrO}^{4-}$, and they can transform each other. When the $\mathrm{pH}$ is reduced, $\mathrm{Cr}_{2} \mathrm{O}_{7}^{2-}$ converted to $\mathrm{HCrO}^{4-}[12]$. When the $\mathrm{pH}$ value is increased, the $\mathrm{H}^{+}$ion is gradually reduced, and the generation of the ferrous ion is reduced. The conversion between $\mathrm{Cr}_{2} \mathrm{O}_{7}^{2-}$ and $\mathrm{HCrO}^{4-}$ was difficult. The removal efficiency of $\mathrm{Cr}$ (VI) was decreased. Therefore, acidic condition for the removal of $\mathrm{Cr}$ (VI) was more favorable.

3)Effect of initial concentration on $\mathrm{Cr}$ (VI) removal

Fig.3(c) showed that the removal efficiency decreased with the increase of the initial concentration of $\mathrm{Cr}(\mathrm{VI})$. Therefore, with the increase of the initial concentration, the rate of remove of $\mathrm{Cr}$ (VI) had little difference. The CFCMC-nZVI has strong activity for the removal of $\mathrm{Cr}$ (VI).

4)Effect of dosage on $\mathrm{Cr}$ (VI) removal

The effects of dosage on $\mathrm{Cr}(\mathrm{VI})$ removal were presented in Fig.3 (d). When the dosage of CF-CMC-nZVI increased, the removal rate of $\mathrm{Cr}$ (VI) increased rapidly. The surface area of nZVI increased as the dosage of CF-CMC-nZVI increased. The effective specific surface area of the $\mathrm{Cr}$ (VI) reaction was also increased, which promoted the reaction rate and removal efficiency. 

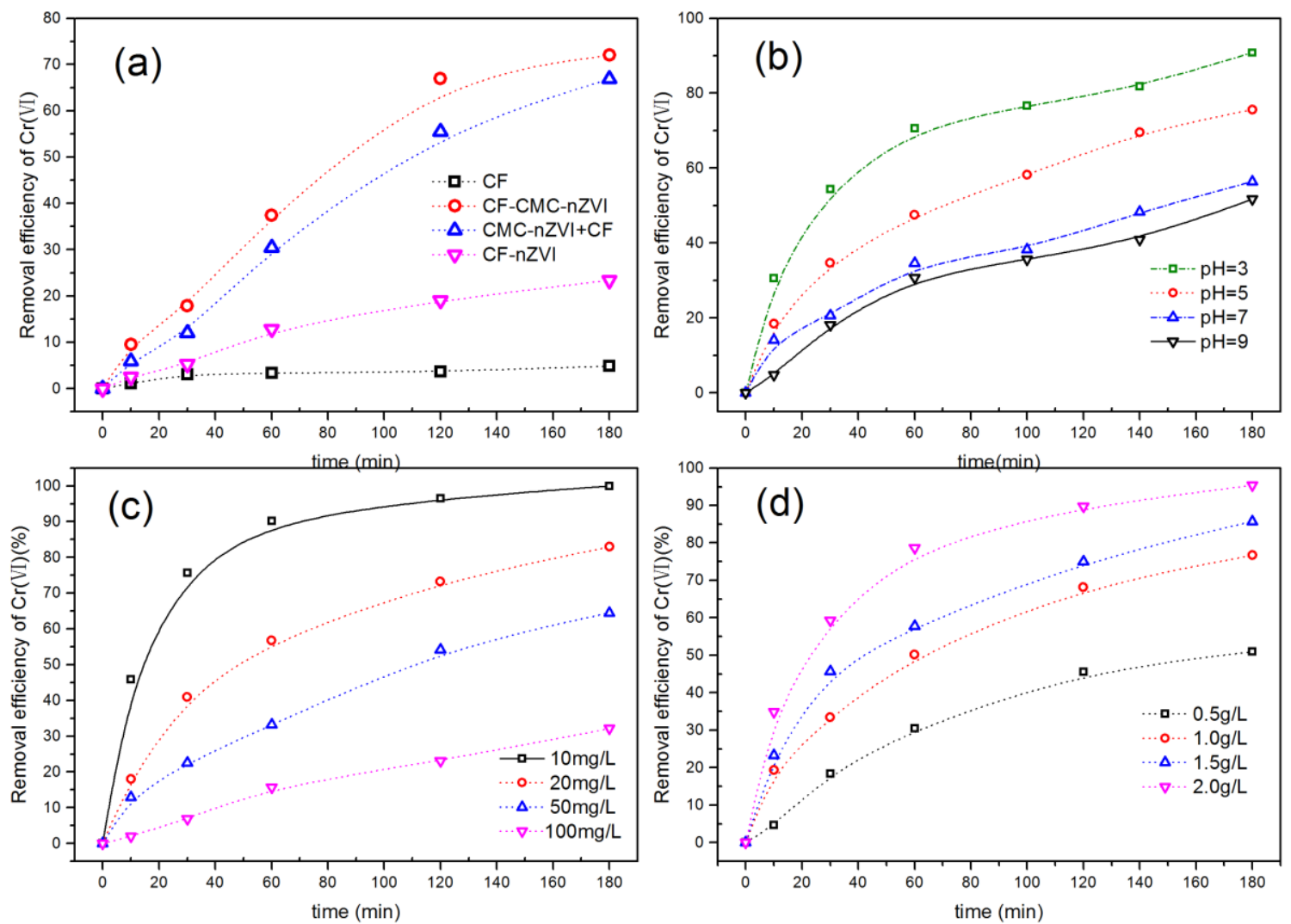

Figure 3. Effect of different materials (a), $\mathrm{pH}$ (b), initial concentrations(c) and dosages of CF-CMC-nZVI (d) on Cr (VI) removal. ( (a) Cr(VI): $20 \mathrm{mg} / \mathrm{L}$, nZVI: 1g/ L, CMC: 5 g/L, CF: 0.2 g, T: 25, pH: 5.5; (b) Cr(VI): 20 mg/L, nZVI: 1g/L, CMC: 5 g/L1, CF: 0.2 g, T: 25; (c) nZVI: 1g/L, CMC: 5 g/L, CF: 0.2 g, T: 25 , pH: 5.5 (d) Cr(VI): 20 mg/L, nZVI: CMC: 1:5, CF: 0.2 g, T: 25, pH: 5.5).

\section{5) Sorption isotherm}

Adsorption isotherms depicts the interaction pathway of pollutants with remediation materials. Fig. 4 showed the sorption isotherms of $\mathrm{Cr}$ (VI) removal on the CF-CMC-nZVI. The linear expression of Langmuir adsorption isotherm equation is expressed in Eq. (3) [13].

$$
\frac{C_{e}}{q_{e}}=\frac{1}{b q_{\max }}+\frac{C_{e}}{q_{\max }}
$$

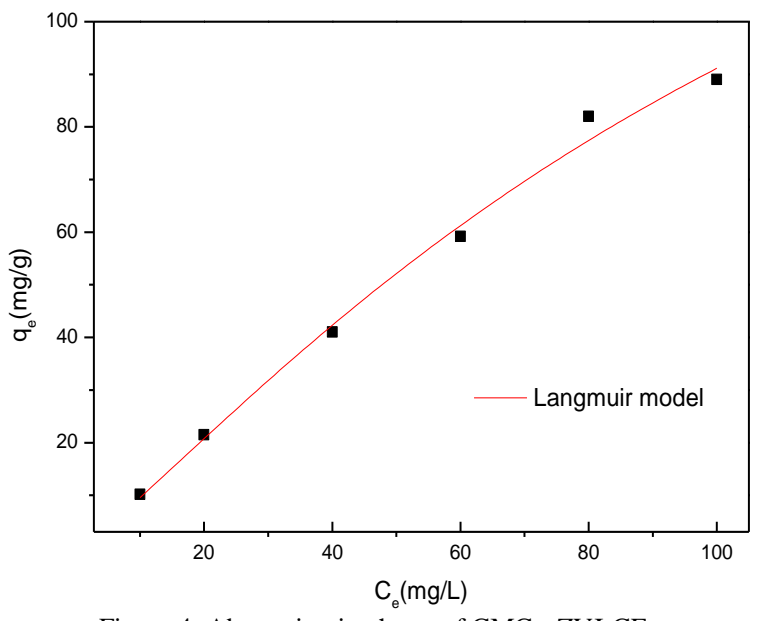

Figure 4. Absorption isotherm of CMC-nZVI-CF

Fitting by Eq. (3) and obtain the $\mathrm{q}_{\max }(217.04 \mathrm{mg} / \mathrm{g})$. The process of $\mathrm{Cr}$ (VI) removal on the CF-CMC-nZVI was Langmuir adsorption, and the adsorption amount gradually approached the maximum sorption capacities $217.04 \mathrm{mg} / \mathrm{g}$. It has the characteristic of Langmuir type isotherm from correlation coefficient ( 0.99$)$.

\section{IV.CONCLUSIONS}

In this work, CF supported CMC-nZVI was prepared. CMC-nZVI-CF was proved the most efficient way to remove 
Cr (VI). The results showed that the CMC-nZVI has a better dispersion and stronger anti-oxidant activity. CF favored the removal of $\mathrm{Cr}$ (VI). It is favorable to remove chromium under acidic conditions. $\mathrm{Cr}$ (VI) removal efficiency increased as increase of the dosage of CF-CMC-nZVI. The process of the treatment of $\mathrm{Cr}$ (VI) by CF-CMC-nZVI was line with the Langmuir adsorption isotherm. CF-CMC-nZVI might offer an effective method to remove $\mathrm{Cr}$ (VI) from wastewater.

\section{ACKNOWLEDGEMENTS}

This work was funded by the Cultivate Discipline Fund of the Shanghai Second Polytechnic University (XXKPY1601) and Shanghai Cooperative Center for WEEE Recycling.

\section{REFERENCES}

[1] E. Gordo, G. Z. Chen and D. J. Fray, Electrochimica Acta, 2004, 49, 2195- 2208

[2] M. B. Hansen, J. D. Johansen and T. Menn, Contact Dermatitis, 2003, $49,206-212$.
[3] F. A. Erturk, G. Agar, E. Arslan, etc., Acta Physiologiae Plantarum, 2014, 36, 1529-1537.

[4] W. X. Zhang, Journal of Nanoparticle Research, 2003, 5, 323-332.

[5] X.-q. Li, D. W. Elliott and W.-x. Zhang, Critical Reviews in Solid State \& Material Sciences, 2006, 31, 111-122.

[6] Z. Zhang, Z. Cui, K. Chen, ect. , Chinese Science Bulletin, 1997, 42, 1535-1538.

[7] W. A. A. And and A. L. Roberts, Environmental Science \& Technology, 2000, 34, 1794-1805.

[8] Z. H. Pang, X. S. Jia, K. Liu, ect., Advanced Materials Research, 2012, 573-574, 155-162.

[9] J. Q. Li, Q. S. Pan, R. Q. Zhang and X. J. Zhou, Advanced Materials Research, 2011, 332-334, 1914-1917.

[10] H. Gu, S. B. Rapole, Y. Huang, D. Cao, Z. Luo, S. Wei and Z. Guo, J.mater.chem.a, 2013, 1, 2011-2021.

[11] R. A. Crane, M. Dickinson, I. C. Popescu and T. B. Scott, Water Research, 2011, 45, 2931-2942.

[12] Q. Wang, N. Cissoko, M. Zhou and X. Xu, Physics \& Chemistry of the Earth Parts A/b/c, 2011, 36, 442-446.

[13] T. Lin, G. D. Yang, G. M. Zeng, ect., Chemical Engineering Journal, 2014, 239, 114-122. 